\title{
MYOCARDITIS IN AUTO-IMMUNE OR AUTO-INFLAMMATORY DISEASES
}

Cloé Comarmond $^{(1,2,3,4)}$, Patrice Cacoub ${ }^{(1,2,3,4)}$

1. Département de Médecine Interne et Immunologie Clinique, Assistance PubliqueHôpitaux de Paris (AP-HP), Groupe Hospitalier Pitié-Salpêtrière, F-75013, Paris, France

2. Département Hospitalo-Universitaire I2B, UPMC Univ Paris 06, F-75013, Paris, France

3. INSERM UMR 7211, F-75005, Paris, INSERM, UMR_S 959, F-75013, Paris, France

4. CNRS, UMR 7211, F-75005, Paris, France

Correspondance: Prof. Patrice Cacoub, Département de Médecine Interne et Immunologie Clinique, Groupe Hospitalier Pitié-Salpêtrière, 83 boulevard de l'hôpital, F-75013, Paris, France

Tel: +33 (0) 1421780 27; fax +33 (0) 1421780 33; email patrice.cacoub@aphp.fr 


\begin{abstract}
Myocarditis is a major cause of heart disease in young patients and a common precursor of heart failure due to dilated cardiomyopathy. Some auto-immune and/or auto-inflammatory diseases may be accompanied by myocarditis, such as sarcoidosis, Behçet's disease, eosinophilic granulomatosis with polyangiitis, myositis, and systemic lupus erythematosus. However, data concerning myocarditis in such auto-immune and/or auto-inflammatory diseases are sparse. New therapeutic strategies should better target the modulation of the immune system, depending on the phase of the disease and the type of underlying auto-immune and/or auto-inflammatory disease.
\end{abstract}

\title{
Key words
}

Myocarditis; autoimmune diseases 
Myocarditis is an inflammation of the heart muscle. Myocarditis is a major cause of heart disease in young patients and a common precursor of heart failure due to dilated cardiomyopathy (1). Myocarditis may present with a wide range of symptoms, ranging from mild dyspnea or chest pain to cardiogenic shock and death. It is difficult to estimate the true incidence of myocarditis. The fulminating forms are exceptional (5 to 10 cases per million inhabitants per year) and their incidence seems stable for several decades (2). Myocarditis result mainly from banal viral infections, but may be also secondary to toxic, allergic or associated with a systemic disease.

Cardiac involvement during auto-immune and/or auto-inflammatory diseases include the pericardium, myocardium, endocardium, valvular tissue, and coronary arteries. Some autoimmune and/or auto-inflammatory diseases may be accompanied by myocarditis, such as sarcoidosis, Behçet's disease, eosinophilic granulomatosis with polyangiitis (EGPA), myositis, and systemic lupus erythematosus (SLE). However, data concerning myocarditis in such autoimmune and/or auto-inflammatory diseases are sparse. The diagnosis is usually made based on clinical presentation, such as dyspnea, fever, chest pain, and/or palpitations, and non-invasive imaging findings, classically echocardiography. Biological manifestations are non-specific and may include the elevation of troponin and/or C-reactive protein. Endomyocardial biopsy still remains the gold standard for diagnosis confirmation (3). However, this procedure is not routinely used because of its low sensitivity and potential complications. Cardiac magnetic resonance (CMR) has changed the management of suspected myocarditis in systemic inflammatory diseases by providing a 'positive' diagnostic test $(4,5)$.

There is considerable interest in the accurate detection of myocardial involvement in auto-immune and/or auto-inflammatory diseases, as it may potentially guide therapy aimed at reducing adverse cardiovascular outcomes. Therapeutic options remain limited for both the acute and chronic phases of myocarditis. Most patients respond well to standard heart failure therapy, although in severe cases, mechanical circulatory support or heart transplantation is indicated. Immunosuppressive and immunomodulatory therapies for myocarditis associated to auto-immune and/or auto-inflammatory diseases have potential benefit but further studies are warranted. Persistent, chronic myocarditis usually has a progressive course but may respond to immunosuppression.

Underlying mechanisms are not completely understood. Autoimmune responses and inflammation are involved in the pathogenesis of myocarditis and its sequela, dilated 
cardiomyopathy. Persistent autoimmune responses have been postulated to underlie the progression from myocarditis to dilated cardiomyopathy. Autoimmune myocarditis is mediated by $\mathrm{CD}^{+} \mathrm{T}$ cells. Transfer of $\mathrm{CD} 4^{+} \mathrm{T}$ cells to severe combined immunodeficient (SCID) mice produced disease, while depletion of $\mathrm{CD}^{+} \mathrm{T}$ cells ameliorated experimental autoimmune myocarditis. T helper 1 (Th1) and Th17 cells infiltrates have been found in hearts of mice after myocarditis induction.

The aim of this review is to provide new insights into myocarditis in systemic auto-immune and/or auto-inflammatory diseases.

\section{Sarcoidosis}

Sarcoidosis is a multi-organ systemic inflammatory disorder characterized by the formation of non-caseating granulomas. Although autopsy studies reveal heart lesions in 20 to $30 \%$ of sarcoid patients, fewer than 5\% suffer from clinical disease. Cardiac sarcoidosis has a predilection for the myocardium and it is likely associated with heart block or arrhythmia resulting in sudden death. Unlike the situation in isolated pulmonary disease, cardiac involvement implies a poor prognosis related to extent and sites of involvement. In a study of 43 patients with myocardial sarcoidosis seen at the Johns Hopkins Hospital from 1889 to 1991, cardiomyopathy was noted in 21 (49\%) and was associated with a mortality of 62\% (6). Other features included syncope in 14 (33\%), heart block in 13 (30\%), and tachy-arrhythmias in 12 (28\%). Granulomatous infiltration of the myocardium may be lethal. The location of myocardial scarring with CMR is typically patchy and in a non-vascular distribution, which is easily differentiated from scarring patterns as a result of ischemic heart disease (7). In a study of Japanese patients with cardiac sarcoidosis, the total number of affected segments on CMR significantly correlated with duration of sarcoidosis in patients with onset in extra-cardiac sites as well as left ventricular ejection fraction (LVEF) and LV diastolic volume (8).

For symptomatic patients, medical treatment may include a combination of glucocorticosteroids (CT) and immunosuppressive agent (IA) as soon as possible (9). In a retrospective French study (10), 39 patients with cardiac sarcoidosis were treated with CS (initial dose prednisone $\sim 1$ $\mathrm{mg} / \mathrm{kg} /$ day) associated with an IA in 13 patients. The average duration of CS therapy was 43 months (range, 6-168 months). During long-term follow-up (58 months), 87\% of the patients improved and 54\% were presumed cured. Importantly, no patient died suddenly. Nine patients relapsed, with a prednisone daily dose lower to $10 \mathrm{mg}$ in five patients and stopped in three patients. All nine relapses were treated with CS alone, or combined with an IA leading to a cure 
in six. Anti-TNF alpha therapy such as infliximab has shown interesting results in refractory cases (11-13). Heart block warrants a permanent pacemaker, while ventricular tachyarrhythmias are typically amiodarone unresponsive, requiring implantation of an implantable defibrillator. Cardiac transplantation is exceptionally required.

\section{Behçet's disease}

Cardiac manifestations related to Behçet's disease (BD) affect particularly young men, during the first years following disease onset. Cardiac complications (up to $6 \%$ of BD patients) include pericarditis, endocardial (aortic regurgitation and less often mitral insufficiency), and myocardial lesions. The latter include myocardial infarction (15\%), myocarditis/endomyocardial fibrosis (8\%), and intra-cardiac thrombosis (right ventricle and atrium). Myocarditis is an unusual association with BD $(14,15)$, found in 2 out of 28 cardiac involvement in an autopsy series (16). Of note, endomyocardial fibrosis may be a sequelae of endocarditis, myocarditis or both, and may be complicated with mural thrombus (14).

Treatment is based on CT, IA and anticoagulant. In a French retrospective study of 52 BD patients with cardiac lesions (17), endomyocardial fibrosis was observed in four (7.7\%) patients and myocardial aneurysm in one (1.9\%). Factors associated with complete remission of cardiac involvement were treatment regimens with oral anticoagulants, IA and colchicine. The 5-year survival rate was $83.6 \%$ and $95.8 \%$ in $\mathrm{BD}$ patients with and without cardiac involvement, respectively. After a median follow-up of 3.0 [1.75-4.2] years, 8 patients had died, due directly to cardiac involvement in 3 cases.

\section{Eosinophilic granulomatosis with polyangiitis}

Eosinophilic granulomatosis with polyangiitis (EGPA, formerly known as Churg-Strauss syndrome) is a rare autoimmune systemic vasculitis with an incidence of less than 3 cases per million. EGPA is a multisystem disorder characterized by asthma, prominent peripheral blood eosinophilia, and vasculitis signs. Heart involvement is observed in $27 \%$ to $47 \%$ of the patients and remains the main predictor of poor long-term prognosis and premature mortality (18). Myocarditis is one of the most common cardiac manifestations in EGPA, presenting from chest pain and palpitations to life-threatening cardiogenic shock and arrhythmia (19). Symptomatic cardiomyopathy carries a poor prognosis and it is responsible for nearly $50 \%$ of the deaths (20). Twenty three patients with EGPA and myocarditis have been reported in the literature. Thirteen out of the $23(56 \%)$ cases involved females and the age at EGPA onset ranged from 2 to 77 
years. Peripheral eosinophilia was reported in all cases and extravascular eosinophils infiltration in 14/18 (78\%). Eosinophil count increases markedly to a level much higher than levels of other forms of EGPA in patients with myocarditis, and the number of white blood cells also increases due to eosinophilia. The mean age at diagnosis of EGPA-myocarditis was 43 years. The risk of myocarditis is increased in patients of 20-30 years old (incidence of myocarditis in EGPA patients is $23 \%$ ). Cardiac manifestations occur later in females than males $(21,22)$. Myocarditis may be associated with a surge in eosinophils, which may suggest the pathogenesis of myocarditis in EGPA patients. Extravascular eosinophil infiltration is due to the significant increase in intravascular eosinophils. When its count increases up to $20 \%$ of total leucocytes count, eosinophils start to infiltrate into the myocardium. Patients are positive for erythrocyte sedimentation rate and CRP level, indicating an inflammation response. Anticytoplasmic neutrophils antibodies (ANCA) are reported in $\sim 40 \%$ of EGPA cases (23); however, EGPA patients with myocarditis are usually ANCA-negative. Among 14 patients with myocardial delayed enhancement on CMRI, FDG-PET scan showed hypofixation in 10, hyperfixation in 2 and normal images in 2 (24). Six patients with normal CMRI also had normal FDG-PET images. EGPA duration at the time of CMRI was shorter for patients with myocardial inflammation than in those with fibrosis. For EGPA patients in remission, CMRI detected subclinical active myocardial lesions (24). Corticosteroids are the first-line therapy for EGPA, resulting in remission and improved survival. When recurrences are frequent or associated with a serious form of necrotizing vasculitis in organs such as myocarditis, the use of an IA such as cyclophosphamide or rituximab is recommended.

\section{Takayasu arteritis}

In patients with Takayasu arteritis, myocarditis can occur and cause LV dysfunction. Cardiac impairment is generally regarded as a consequence of arterial hypertension, pulmonary vascular involvement, coronary artery disease and aortic regurgitation (25). However, auto-immune cytotoxic mechanisms similar to those found in arterial tissue may also contribute to cardiac impairment in Takayasu's arteritis. CMR using gadolinium can give useful information about the anatomy of aorta and major vessels and the presence of myocardial inflammation $(26,27)$. CMR may characterize myocardial tissue, and thus potentially detect myocardial edema, increased blood flow and capillary leakage, necrosis and subsequent fibrosis that occurs in myocarditis. In addition, CMR can detect subtle regional or global contractile dysfunction. CMR is now often able to provide a positive diagnosis of myocarditis. Computed tomography (CT) could be proposed in clinically suspected myocarditis because it has the advantage of 
ruling out coronary artery disease and of delineating the inflamed myocardium with specific iodine imaging. The $18 \mathrm{~F}$-fluorodeoxyglucose uptake is not only a sensitive marker of inflammation, but also a quantifiably parameter for disease activity that could complement CMR in the detection, differential diagnosis, and monitoring of myocarditis. FDG PET scan could be effective in following up the treatment outcome of myocarditis. Earlier studies have found a lymphocytic infiltration consistent with myocarditis in approximately fifty percent of sixteen Indian cases of Takayasu arteritis (27,28). Breinholt et al (30) demonstrated increases in HLA-DR on cardiac endothelium and immune complex deposition in the walls of small myocardial vessels, suggesting the presence of a vasculitic process within the myocardium. Takeda et al reported that HLA classes I and II, and ICAM-I were present on the ventricular myocytes of a case of Takayasu myocarditis (31). In consideration of the age of the patients susceptible to heart failure (below 20 years old) (32), active cardiac inflammation may primarily be attributable to LV dysfunction in Takayasu arteritis. Immunosuppressive therapy may be useful for myocardial involvement of Takayasu arteritis. Talwar et al (28) reported that combined therapy of prednisolone $(1 \mathrm{mg} / \mathrm{kg} / \mathrm{d})$ and oral cyclophosphamide $(2 \mathrm{mg} / \mathrm{kg} / \mathrm{d})$ over twelve weeks improved clinical and hemodynamic states, and myocardial morphology. LVEF improved from $33 \%$ to $49 \%$, and repeated endomyocardial biopsies after treatment showed healed myocarditis (disappearance of the infiltrating $\mathrm{T}$ suppressor lymphocytes). These data suggest that Takayasu myocarditis might be the result of a cytotoxicity.

\section{Systemic lupus erythematosus}

Cardiovascular involvement in SLE represents a significant cause of morbidity and mortality. SLE associated myocarditis was shown to shorten the survival and is more common amongst patients with higher disease activity. Postmortem studies from the 1950-60s reported myocarditis in up to $57 \%$ (72/126) of patients with SLE, indicating that subclinical myocardial involvement may commonly occur. Lupus myocarditis is a severe manifestation of SLE. It can be the first manifestation of the disease or it can occur during the follow up, in particular in untreated patients (33). In a recent French series of 29 lupus myocarditis, myocarditis was the first sign of SLE in $58.6 \%$ of cases (34). The CMR revealed delayed gadolinium enhancement in $9 / 13(69 \%)$ patients.

The treatment of lupus myocarditis has in general, been empirical. With the use of CT, IA and cardiovascular support, the long-term prognosis is usually favorable (35). Steroids have been the mainstay of treatment either orally or as intravenous pulses (36). As for other major organ 
involvement in SLE, cyclophosphamide has been used with success (37). There are also rare case reports of improvement with high dose intravenous immunoglobulin (38) and plasmapheresis (39). Extracorporeal membrane oxygenation has been used successfully in lupus myocarditis associated with cardiogenic shock (40).

\section{Systemic sclerosis}

Systemic sclerosis ( $\mathrm{SSc}$ ) is an auto-immune connective tissue disorder characterised, at the end of the pathogenic process, by multi-organ fibrosis. Cardiac involvement in SSc is estimated at 15-35\%. Myocardial involvement is often subclinical with higher prevalence on autopsy or endomyocardial biopsy studies (41). Overt cardiac disease is associated with poor prognosis, with a reported $70 \%$ mortality at 5 years. In a cohort of 181 patients with SSc (42), 7 (3.8\%) patients newly developed clinical symptoms of heart disease (heart failure, chest pain, and palpitation); all of them showed mild but persistent increase in cardiac enzymes. In all patients, histology showed upregulation of endothelium adhesion molecules and infiltration of activated T lymphocytes, with (acute/active myocarditis in six patients) or without (chronic/borderline myocarditis in one patient) myocyte necrosis. Of note, parvovirus B19 genome was detected in 3. None showed occlusion of coronary arteries or microvessels. Immunosuppressive therapy improved symptoms and led to cardiac enzyme negativation. However, two patients died of sudden death during follow-up.

\section{Mixed connective tissue disease}

Mixed connective tissue disease (MCTD) is an overlap autoimmune syndrome which may include patterns of SLE, SSc and myositis. The frequency of cardiac involvement in patients with MCTD varies between $11 \%$ and $85 \%$, depending upon patient selection and definitions of cardiac involvement as well as upon methods used to detect cardiac manifestations. The most frequently observed cardiac manifestations were pericarditis (29\%), and mitral valve prolapse (26\%) (43). Other observed cardiac manifestations included myocarditis, conduction disturbances, and abnormal LV diastolic filling pattern on echocardiography. The most significant clinical cardiovascular problem in MCTD is pulmonary hypertension which is associated with a poor prognosis. Myocardial involvement in MCTD, as in SLE, is associated with a relatively poor prognosis (44). Myocarditis may be an important complication in patients with high titer of antibody to nuclear ribonucleoprotein. Despite treatment with CT and cyclophosphamide, progressive myocarditis resulted in death in a case of young black woman $(45)$. 


\section{Antiphospholipid syndrome}

The antiphospholipid syndrome (APS) is characterized by recurrent arterial or venous thromboses, thrombocytopenia, fetal losses and the presence of anti-phospholipid antibodies. Other obstetrical conditions associated with APS include early-onset pre-eclampsia, eclampsia, intra-uterine growth restriction, placental abruption, and preterm delivery. Secondary APS refers to the association with SLE, rheumatologic or other autoimmune disorders. Cardiac disease in APS include valvular disease (i.e. nonbacterial thrombotic vegetations and peripheral embolization) in 35 to $50 \%$ of primary APS, coronary occlusion (angina, myocardial infarction) in $5 \%$ of primary APS, whereas LV dysfunction appears to be most associated with SLE-APS $(23-32 \%)$. The incidence of ventricular dysfunction in primary APS is unknown. Intra-cardiac thrombi and pulmonary hypertension, although rare, are also severe cardiovascular manifestations of APS. All these process are thrombotic in nature and not inflammatory. Myocarditis is rarely described in APS $(43,46)$, especially during pregnancy. When it does occur it has been specifically associated with SLE and MCTD. There is no known effective treatment or recommendations by the committee consensus report.

Approximately, $1 \%$ of patients with APS develop a very severe complication characterized by multiple thromboses affecting mainly small vessels, called catastrophic APS (CAPS). Cardiac manifestations of CAPS have been recently reported in a large series of 515 patients with heart failure (44\%), myocardial infarction (30\%), valvulopathy (28\%), and Libman Sacks endocarditis (13\%) (47). Although thrombotic in nature, some degree of inflammation may be found in target organs. Patients with CAPS associated with SLE are usually young females presenting with a severe clinical phenotype and high mortality. Conversely, CAPS cases diagnosed in the elderly are rarely associated with SLE and malignancies are commonly described. Clinically, CAPS associated with SLE show a high frequency of cardiac valve involvement leading to cerebrovascular disease, and a high frequency of clinical features of microangiopathic phenomena and cytokine storm (higher frequency of livedo reticularis and Raynaud phenomena). Therefore, SLE-associated CAPS patients require a different treatment approach, e.g. cyclophosphamide as an add-on therapy to improve the outcomes.

\section{Cryoglobulinemia vasculitis}

Cardiac involvement is a rare manifestation of mixed cryoglobulinemia vasculitis. The prevalence of cardiac manifestation in hepatitis $\mathrm{C}$ virus (HCV)-related mixed cryoglobulinemia is $4 \%$ (48). In a retrospective study reporting cardiac involvement in HCV-related vasculitis, 
cardiac involvement was associated with B-cell lymphoma and life-threatening manifestations (49). All cardiac manifestations were reversible early after the initiation of CT and IA. However, after a median follow-up period of 19 months, 3 (43\%) patients had died. Respective 6-month, 1-year, and 2-year survival rates in patients with and without cardiac involvement were $86 \%$ and $99 \%, 71 \%$ and $96 \%$, and $48 \%$ and $90 \%$ (hazard ratio 5.01, p $=0.003$ ). Despite favorable early outcomes, patients with cardiac damage had poorer survival than those without.

\section{Antisynthetase syndrome}

The antisynthetase (AS) syndrome is characterized by autoimmune myopathy, interstitial lung disease, cutaneous involvement, arthritis, fever, and the presence of myositis-specific autoantibodies (directed against tRNA-synthetases). The prevalence of myocarditis in AS is 3\% to $4 \%$ and it is not linked to autoantibody specificity (50). In a French retrospective study of 12 cases of myocarditis in AS patients, myocarditis was a part of the first AS manifestations in $42 \%$. It was asymptomatic (17\%) or revealed by features of acute $(33 \%)$ or subacute $(50 \%)$ cardiac failure (51). Myocarditis was always associated with an active myositis $(43,52)$. Cardiac MRI revealed late hypersignals in T1-images (73\%). Half of the patients required intensive care. Ten (83\%) patients received dedicated cardiotropic drugs. Steroids and one IA were given in all cases. After a median follow-up of 11 months (0-84), 75\% of AS patients with myocarditis recovered whereas $25 \%$ developed a chronic cardiac insufficiency. No patient died. In a French study, treatment with intravenous methylprednisolone followed by oral CT and IA seems to be effective for treating myocardial involvement in patients with idiopathic inflammatory myopathies, either alone or presenting as overlap syndromes (53). Cardiovascular MRI is a non-invasive technique that may be a powerful tool for diagnosis and monitoring of myocardial inflammation in this setting. Although the prognosis is relatively good, myocarditis remains a severe condition and should be carefully considered as a possible manifestation in active AS patients.

In conclusion, myocarditis is a rare but severe manifestation of some auto-immune and/or autoinflammatory diseases. Therapeutic progress in the last decades, in particular through the use of advanced cardiopulmonary resuscitation and hemodynamic support (pharmacological and mechanical circulatory assistance) have made possible to better characterize the clinical and histological forms of myocarditis. When a fulminant form is suspected, it is necessary to quickly contact a medical and surgical center with the capacity to set up an Extra-Corporeal Membrane 
Oxygenation, the more often by using a mobile circulatory assistance unit. The decision should be made according to the risk of worsening disease and prognosis if visceral malfunctions or cardiac arrest occur before placing the device. In the future, new therapeutic strategies should better target the modulation of the immune system, depending on the phase of the disease and the type underlying auto-immune and/or auto-inflammatory disease associated to myocarditis. 


\section{Take-home messages}

- Myocarditis is a potentially life-threatening disease that primarily affects young adults with sometimes devastating consequences, including sudden death.

- Diagnosis and treatment of myocarditis in the clinic can be difficult as main symptoms are non-specific.

- Myocarditis is a rare but severe manifestation of some auto-immune and/or autoinflammatory diseases, mainly sarcoidosis, Behçet's disease, eosinophilic granulomatosis with polyangiitis, systemic lupus and Takayasu arteritis.

- Non-invasive strategies for confirming the diagnosis of myocarditis, including cardiac MRI, are promising but require additional validation.

- Glucocorticosteroids and immunosuppressive agents remain the cornerstone of treatment. New therapeutic strategies should better target the modulation of the immune system, depending on the phase of the disease and the type of underlying auto-immune and/or auto-inflammatory disease. 


\section{References}

1. Eckart RE, Scoville SL, Campbell CL, Shry EA, Stajduhar KC, Potter RN, et al. Sudden death in young adults: a 25-year review of autopsies in military recruits. Ann Intern Med 2004;141:829-834.

2. McCarthy RE, Boehmer JP, Hruban RH, Hutchins GM, Kasper EK, Hare JM, et al. Long-term outcome of fulminant myocarditis as compared with acute (nonfulminant) myocarditis. $N$ Engl $\mathrm{J}$ Med 2000;342:690-695.

3. Arbustini E, Gavazzi A, Dal Bello B, Morbini P, Campana C, Diegoli M, et al. Ten-year experience with endomyocardial biopsy in myocarditis presenting with congestive heart failure: frequency, pathologic characteristics, treatment and follow-up. G Ital Cardiol 1997;27:209-223.

4. Yilmaz A, Ferreira V, Klingel K, Kandolf R, Neubauer S, Sechtem U. Role of cardiovascular magnetic resonance imaging $(\mathrm{CMR})$ in the diagnosis of acute and chronic myocarditis. Heart Fail Rev 2013;18:747-760.

5. Mavrogeni S, Dimitroulas T, Sfikakis PP, Kitas GD. Heart involvement in rheumatoid arthritis: multimodality imaging and the emerging role of cardiac magnetic resonance. Semin Arthritis Rheum 2013;43:314-324.

6. Johns CJ, Michele TM. The clinical management of sarcoidosis. A 50-year experience at the Johns Hopkins Hospital. Medicine (Baltimore) 1999;78:65-111.

7. Smedema J-P, Truter R, Klerk PA de, Zaaiman L, White L, Doubell AF. Cardiac sarcoidosis evaluated with gadolinium-enhanced magnetic resonance and contrast-enhanced 64-slice computed tomography. Int J Cardiol 2006;112:261-263.

8. Watanabe E, Kimura F, Nakajima T, Hiroe M, Kasai Y, Nagata M, et al. Late gadolinium enhancement in cardiac sarcoidosis: characteristic magnetic resonance findings and relationship with left ventricular function. J Thorac Imaging 2013;28:60-66.

9. Nunes H, Freynet O, Naggara N, Soussan M, Weinman P, Diebold B, et al. Cardiac sarcoidosis. Semin Respir Crit Care Med 2010;31:428-441.

10. Chapelon-Abric C, Zuttere D de, Duhaut P, Veyssier P, Wechsler B, Huong DLT, et al. Cardiac sarcoidosis: a retrospective study of 41 cases. Medicine (Baltimore) 2004;83:315-334.

11. Chapelon-Abric C, Saadoun D, Biard L, Sene D, Resche-Rigon M, Hervier B, et al. Long-term outcome of infliximab in severe chronic and refractory systemic sarcoidosis: a report of 16 cases. Clin Exp Rheumatol 2015;33:509-515.

12. Barnabe C, McMeekin J, Howarth A, Martin L. Successful treatment of cardiac sarcoidosis with infliximab. J Rheumatol 2008;35:1686-1687.

13. Uthman I, Touma Z, Khoury M. Cardiac sarcoidosis responding to monotherapy with infliximab. Clin Rheumatol 2007;26:2001-2003.

14. Higashihara M, Mori M, Takeuchi A, Ogita T, Miyamoto T, Okimoto T. Myocarditis in Behcet's disease--a case report and review of the literature. J Rheumatol 1982;9:630-633.

15. Maeda S, Tamura A, Zaizen H, Takahashi N. Behçet's disease complicated by giant-cell myocarditis. Intern Med Tokyo Jpn 2014;53:1721. 
16. Lakhanpal S, Tani K, Lie JT, Katoh K, Ishigatsubo Y, Ohokubo T. Pathologic features of Behçet's syndrome: a review of Japanese autopsy registry data. Hum Pathol 1985;16:790-795.

17. Geri G, Wechsler B, Thi Huong DL, Isnard R, Piette J-C, Amoura Z, et al. Spectrum of cardiac lesions in Behçet disease: a series of 52 patients and review of the literature. Medicine (Baltimore) 2012;91:25-34.

18. Cottin V, Bel E, Bottero P, Dalhoff K, Humbert M, Lazor R, et al. Revisiting the systemic vasculitis in eosinophilic granulomatosis with polyangiitis (Churg-Strauss): A study of 157 patients by the Groupe d'Etudes et de Recherche sur les Maladies Orphelines Pulmonaires and the European Respiratory Society Taskforce on eosinophilic granulomatosis with polyangiitis (Churg-Strauss). Autoimmun Rev 2017;16:1-9.

19. Courand P-Y, Croisille P, Khouatra C, Cottin V, Kirkorian G, Bonnefoy E. Churg-Strauss syndrome presenting with acute myocarditis and cardiogenic shock. Heart Lung Circ 2012;21:178-181.

20. Guillevin L, Pagnoux C, Seror R, Mahr A, Mouthon L, Le Toumelin P. The Five-Factor Score revisited: assessment of prognoses of systemic necrotizing vasculitides based on the French Vasculitis Study Group (FVSG) cohort. Medicine (Baltimore) 2011;90:19-27.

21. Shanks M, Ignaszewski AP, Chan SY, Allard MF. Churg-Strauss syndrome with myocarditis manifesting as acute myocardial infarction with cardiogenic shock: case report and review of the literature. Can J Cardiol 2003;19:1184-1188.

22. Qiao L, Gao D. A case report and literature review of Churg-Strauss syndrome presenting with myocarditis. Medicine (Baltimore) 2016;95:e5080.

23. Comarmond C, Pagnoux C, Khellaf M, Cordier J-F, Hamidou M, Viallard J-F, et al. Eosinophilic granulomatosis with polyangiitis (Churg-Strauss): Clinical characteristics and long-term followup of the 383 patients enrolled in the French Vasculitis Study Group cohort. Arthritis Rheum 2013;65:270281.

24. Marmursztejn J, Guillevin L, Trebossen R, Cohen P, Guilpain P, Pagnoux C, et al. Churg-Strauss syndrome cardiac involvement evaluated by cardiac magnetic resonance imaging and positronemission tomography: a prospective study on 20 patients. Rheumatol Oxf Engl 2013;52:642-650.

25. Lupi-Herrera E, Sánchez-Torres G, Marcushamer J, Mispireta J, Horwitz S, Vela JE. Takayasu's arteritis. Clinical study of 107 cases. Am Heart J 1977;93:94-103.

26. Mavrogeni S, Manoussakis MN. Myocarditis and subclavian stenosis in Takayasu arteritis. Int J Cardiol 2011;148:223-224.

27. Comarmond C, Cluzel P, Toledano D, Costedoat-Chalumeau N, Isnard R, Gaudric J, et al. Findings of cardiac magnetic resonance imaging in asymptomatic myocardial ischemic disease in takayasu arteritis. Am J Cardiol 2014;113:881-887.

28. Talwar KK, Chopra P, Narula J, Shrivastava S, Singh SK, Sharma S, et al. Myocardial involvement and its response to immunosuppressive therapy in nonspecific aortoarteritis (Takayasu's disease)--a study by endomyocardial biopsy. Int J Cardiol 1988;21:323-334.

29. Sharma BK, Jain S, Radotra BD. An autopsy study of Takayasu arteritis in India. Int J Cardiol 1998;66 Suppl 1:S85-90; discussion S91. 
30. Breinholt JP 3rd, Tristani-Firouzi M, Bohnsack JF, Shaddy RE. Evidence for early vessel involvement in the dysfunctional myocardium of Takayasu's arteritis. Pediatr Cardiol 2001;22:74-76.

31. Takeda N, Takahashi T, Seko Y, Maemura K, Nakasone H, Sakamoto K, et al. Takayasu myocarditis mediated by cytotoxic T lymphocytes. Intern Med Tokyo Jpn 2005;44:256-260.

32. Talwar KK, Kumar K, Chopra P, Sharma S, Shrivastava S, Wasir HS, et al. Cardiac involvement in nonspecific aortoarteritis (Takayasu's arteritis). Am Heart J 1991;122:1666-1670.

33. Zawadowski GM, Klarich KW, Moder KG, Edwards WD, Cooper LT. A contemporary case series of lupus myocarditis. Lupus 2012;21:1378-1384.

34. Thomas G, Cohen Aubart F, Chiche L, Haroche J, Hié M, Hervier B, et al. Lupus Myocarditis: Initial Presentation and Longterm Outcomes in a Multicentric Series of 29 Patients. J Rheumatol 2017;44:24-32.

35. Appenzeller S, Pineau CA, Clarke AE. Acute lupus myocarditis: Clinical features and outcome. Lupus 2011;20:981-988.

36. Frustaci A, Gentiloni N, Caldarulo M. Acute myocarditis and left ventricular aneurysm as presentations of systemic lupus erythematosus. Chest 1996;109:282-284.

37. Ueda T, Mizushige K, Aoyama T, Tokuda M, Kiyomoto H, Matsuo H. Echocardiographic observation of acute myocarditis with systemic lupus erythematosus. Jpn Circ J 2000;64:144-146.

38. Sherer $Y$, Levy $Y$, Shoenfeld Y. Marked improvement of severe cardiac dysfunction after one course of intravenous immunoglobulin in a patient with systemic lupus erythematosus. Clin Rheumatol 1999;18:238-240.

39. Tamburino C, Fiore CE, Foti R, Salomone E, Di Paola R, Grimaldi DR. Endomyocardial biopsy in diagnosis and management of cardiovascular manifestations of systemic lupus erythematosus (SLE). Clin Rheumatol 1989;8:108-112.

40. Leung $\mathrm{MCH}$, Harper RW, Boxall J. Extracorporeal membrane oxygenation in fulminant myocarditis complicating systemic lupus erythematosus. Med J Aust 2002;176:374-375.

41. Fernandes F, Ramires FJA, Arteaga E, lanni BM, Bonfá ESDO, Mady C. Cardiac remodeling in patients with systemic sclerosis with no signs or symptoms of heart failure: an endomyocardial biopsy study. J Card Fail 2003;9:311-317.

42. Pieroni M, De Santis M, Zizzo G, Bosello S, Smaldone C, Campioni M, et al. Recognizing and treating myocarditis in recent-onset systemic sclerosis heart disease: potential utility of immunosuppressive therapy in cardiac damage progression. Semin Arthritis Rheum 2014;43:526535.

43. Lundberg IE. Cardiac involvement in autoimmune myositis and mixed connective tissue disease. Lupus 2005;14:708-712.

44. Lash AD, Wittman AL, Quismorio FP. Myocarditis in mixed connective tissue disease: clinical and pathologic study of three cases and review of the literature. Semin Arthritis Rheum 1986;15:288-296. 
45. Whitlow PL, Gilliam JN, Chubick A, Ziff M. Myocarditis in mixed connective tissue disease. Association of myocarditis with antibody to nuclear ribonucleoprotein. Arthritis Rheum 1980;23:808815.

46. Marnach M, VanWinter J, Watson W. Myocarditis: an unusual cause of postpartum fever in pregnancy complicated by antiphospholipid syndrome. Am J Perinatol 2007;24:405-408.

47. Rodríguez-Pintó I, Moitinho M, Santacreu I, Shoenfeld Y, Erkan D, Espinosa G, et al. Catastrophic antiphospholipid syndrome (CAPS): Descriptive analysis of 500 patients from the International CAPS Registry. Autoimmun Rev 2016;15:1120-1124.

48. Cacoub P, Comarmond C, Domont F, Savey L, Saadoun D. Cryoglobulinemia Vasculitis. Am J Med 2015.

49. Terrier B, Karras A, Cluzel P, Collet J-P, Sène D, Saadoun D, et al. Presentation and prognosis of cardiac involvement in hepatitis C virus-related vasculitis. Am J Cardiol 2013;111:265-272.

50. Sharma K, Orbai A-M, Desai D, Cingolani OH, Halushka MK, Christopher-Stine L, et al. Brief report: antisynthetase syndrome-associated myocarditis. J Card Fail 2014;20:939-945.

51. Dieval C, Deligny C, Meyer A, Cluzel P, Champtiaux N, Lefevre G, et al. Myocarditis in Patients With Antisynthetase Syndrome: Prevalence, Presentation, and Outcomes. Medicine (Baltimore) 2015;94:e798.

52. Schwartz T, Diederichsen LP, Lundberg IE, Sjaastad I, Sanner H. Cardiac involvement in adult and juvenile idiopathic inflammatory myopathies. RMD Open 2016;2:e000291.

53. Allanore Y, Vignaux O, Arnaud L, Puéchal X, Pavy S, Duboc D, et al. Effects of corticosteroids and immunosuppressors on idiopathic inflammatory myopathy related myocarditis evaluated by magnetic resonance imaging. Ann Rheum Dis 2006;65:249-252. 
Table 1. Main characteristics of myocarditis in auto-immune and/or auto-inflammatory diseases,

\begin{tabular}{|c|c|c|c|c|}
\hline $\begin{array}{l}\text { Auto- } \\
\text { immune/auto- } \\
\text { inflammatory } \\
\text { disease }\end{array}$ & $\begin{array}{c}\text { Myocarditis } \\
\text { prevalence and } \\
\text { main } \\
\text { manifestations }\end{array}$ & $\begin{array}{l}\text { Performances of } \\
\text { cardiac imaging }\end{array}$ & $\begin{array}{l}\text { Treatment } \\
\text { approach }\end{array}$ & Prognosis \\
\hline Sarcoidosis & $\begin{array}{c}10-15 \% \\
\text { syncope, heart } \\
\text { block, tachy- } \\
\text { arrhythmias, } \\
\text { sudden death }\end{array}$ & $\begin{array}{l}\text { CMR : patchy and } \\
\text { non-vascular } \\
\text { distribution }\end{array}$ & $\begin{array}{c}\text { prednisone } \\
\text { cyclophosphamide } \\
\text { anti-TNF alpha }\end{array}$ & poor \\
\hline Behçet's disease & $\begin{array}{c}0.5 \% \\
\text { young men } \\
\text { congestive heart } \\
\text { failure }\end{array}$ & no data & $\begin{array}{c}\text { prednisone } \\
\text { colchicine } \\
\text { oral anticoagulant } \\
\text { immunosuppressive } \\
\text { agent } \\
\end{array}$ & poor \\
\hline $\begin{array}{l}\text { Eosinophilic } \\
\text { granulomatosis } \\
\text { with polyangiitis }\end{array}$ & $\begin{array}{c}20-30 \% \\
\text { chest pain, } \\
\text { palpitations, } \\
\text { cardiogenic shock, } \\
\text { arrhythmia } \\
\text { ANCA negativity }\end{array}$ & $\begin{array}{l}\text { CMR : myocardial } \\
\text { oedema, increased } \\
\text { blood flow and } \\
\text { capillary leakage, } \\
\text { necrosis and } \\
\text { subsequent fibrosis }\end{array}$ & $\begin{array}{c}\text { prednisone } \\
\text { cyclophosphamide } \\
\text { rituximab }\end{array}$ & poor \\
\hline $\begin{array}{l}\text { Takayasu } \\
\text { arteritis }\end{array}$ & $\begin{array}{c}\text { no data } \\
\text { women } \\
\text { dyspnea and } \\
\text { ventricular } \\
\text { dysfunction }\end{array}$ & $\begin{array}{l}\text { CMR : high signal } \\
\text { in ventricular wall, } \\
\text { myocardial } \\
\text { inflammation and } \\
\text { oedema, late- } \\
\text { gadolinium } \\
\text { enhanced with } \\
\text { ventricular wall } \\
\text { enhancement } \\
\text { CT : exclusion of } \\
\text { coronary disease } \\
\text { FDG PET : } \\
\text { treatment outcome }\end{array}$ & $\begin{array}{c}\text { prednisone } \\
\text { cyclophosphamide }\end{array}$ & poor \\
\hline Systemic lupus & $\begin{array}{c}57 \% \\
\text { subclinical }\end{array}$ & $\begin{array}{c}\text { CMR : } \\
\text { myocarditis } \\
\text { diagnosis and } \\
\text { response to anti- } \\
\text { inflammatory } \\
\text { treatment }\end{array}$ & $\begin{array}{c}\text { prednisone } \\
\text { cyclophosphamide } \\
\text { i.v. immunoglobulins } \\
\text { plasmapheresis }\end{array}$ & $\begin{array}{l}\text { usually } \\
\text { favorable }\end{array}$ \\
\hline
\end{tabular}

ANCA, anti-cytoplasmic neutrophils antibodies; CMR, cardiac magnetic resonance; CT, computed tomography scanner; FDG PET, 18F-fluorodeoxyglucose scanner 


\section{Figure 1. Algorithm for myocarditis in auto-immune/auto-inflammatory diseases}

Young adult, chest pain, palpitations, cardiogenic shock, sudden death

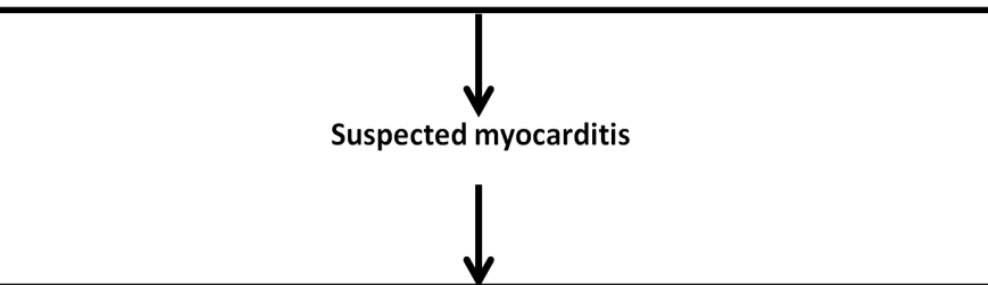

- $\quad$ ECG : sinus tachycardia, QT prolongation, diffuse T wave inversion, ventricular arrhythmias, AV conduction defect

- Echocardiography : ventricular dysfunction, abnormal contractility of interventricular septum

- Elevation of troponin and/or BNP

- $\quad$ Cardiac MR : visualise entire myocardium, guide biopsy, follow disease course and response to Rx

Exclusion coronary artery disease

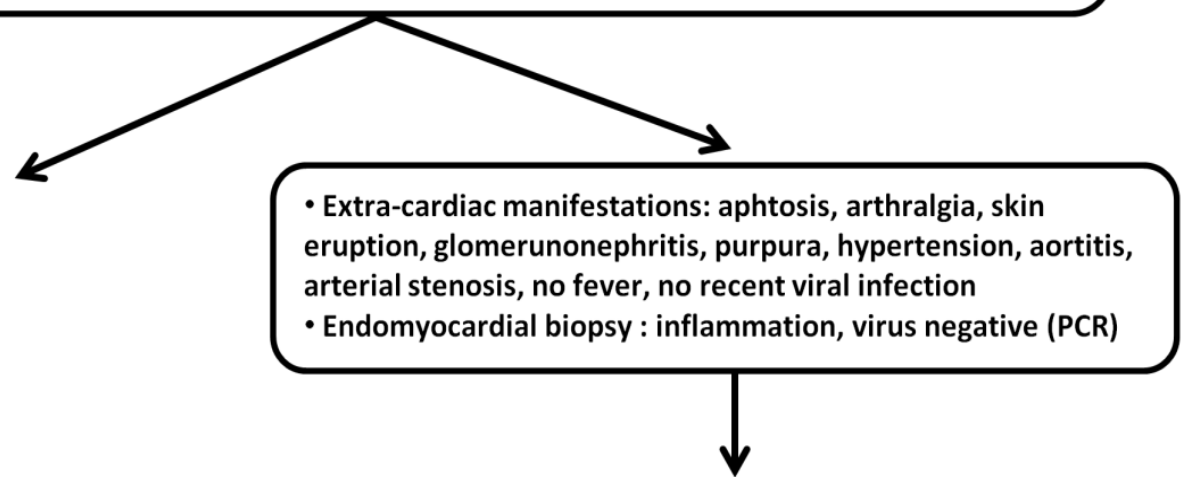

Suspected autoimmune disease

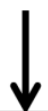

- AAN, anti-DNA native, anti-phospholipid Ab, dot-myositis, ANCA, angiotensin-converting enzyme, cryoglobulinemia

- MR, CT, FDG PET

- Biopsy (skin, lung, salivary gland, kidney): granuloma, vasculitis

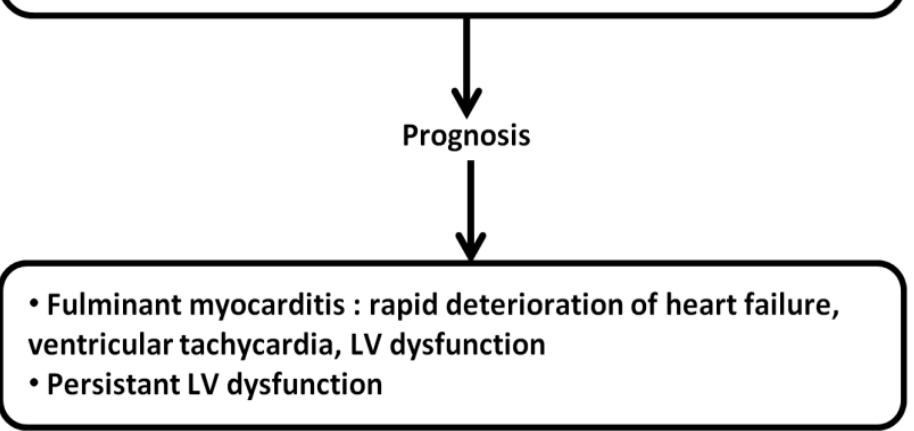

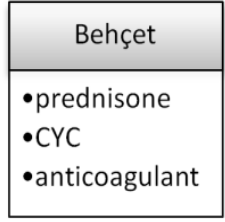

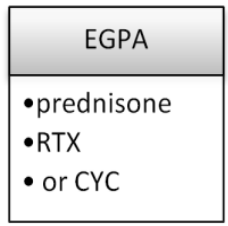

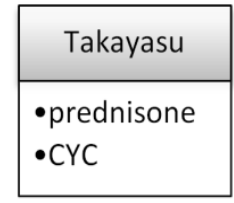

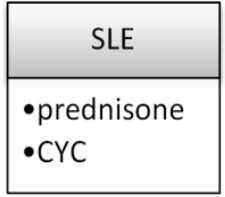

ANA, anti-nuclear antibodies; ANCA, anti-cytoplasmic neutrophils antibodies; BNP, B-type Natriuretic Peptide; CT, computed tomography scanner; CYC, cyclophosphamide; ECG, 
electrocardiogram; EGPA, eosinophilic granulomatous with polyangiitis; FDG PET, 18Ffluorodeoxyglucose scanner; LV, left ventricular; MR, magnetic resonance; RTX, rituximab; SLE, systemic lupus erythematosus; anti-TNF $\alpha$, anti-Tumor Necrosis Factor alpha 